\title{
cmaJOPEN
}

\section{Identifying what matters most for the health of older adults in Alberta: results from a James Lind Alliance Research Priority Setting Partnership}

\author{
Heather M. Hanson PhD, Katherine Cowan MA, Adrian Wagg MBBS
}

\section{Abstract}

Background: As the number of older adults continues to increase, addressing their health becomes increasingly important for both the population and the health care system. The aim of this priority setting partnership was to use direct engagement with older adults, caregivers and health care providers to identify and prioritize the most important topics on the health of older adults that should be addressed by future research.

Methods: We followed the James Lind Alliance method. We conducted an initial online and paper survey from Jan. 22 to May 2 , 2018, with older adults in Alberta aged 65 years and older to identify what respondents saw as being most important for the health of older adults. We formed responses into summary questions and checked them against existing evidence. We administered a second survey (July 3 to Aug. 2, 2018) to shortlist summary questions and held an in-person workshop (Aug. 30, 2018) to rank the list through discussion and shared decision-making.

Results: We recruited 670 participants (32.7\% older adults, $19.7 \%$ caregivers, $46.9 \%$ health and social care workers) in the initial survey to tell us what topics on the health of older adults mattered most to them. Over 3000 responses generated 101 summary questions, of which only 4 were completely answered by existing evidence. The second prioritization survey was completed by 232 participants (28.4\% older adults, $24.6 \%$ care partners, $47.0 \%$ health and social care workers) to produce a shortlist of 22 high priority questions. Twenty-two attendees participated in the summary workshop to create a prioritized list of 10 questions for future research that address aspects of the health system, provision of care and living well in older adulthood.

Interpretation: Older adults, caregivers and clinicians collectively produced a prioritized list of questions that matter most to older adults' health in Alberta. Provincial researchers and research funders should consider these unmet knowledge needs of end-users in future endeavours.

\section{A} $\mathrm{s}$ the number of older adults $(\geq 65 \mathrm{yr})$ continues to increase, ${ }^{1,2}$ addressing their health becomes increasingly important for both this population and the health care system. The Seniors Health Strategic Clinical Network in Alberta aims to improve health care services and practices for older Albertans through health system transformation. ${ }^{3}$ With the limited availability of research dollars, the identification and pursuit of priority health research questions is vital to improve health outcomes and system sustainability.

There is growing emphasis on the need to conduct research that is guided and conducted with meaningful patient engagement. ${ }^{4,5}$ The improved fit between knowledge needs and knowledge production is a compelling outcome of this approach. Patient-oriented clinical research also aligns with our team's commitment to patient- and family-centred care with patients as integral members of the health care team. ${ }^{6}$ Research that meets the needs of end-users decreases the risk of wasting valuable public resources on findings with low relevance, impact or real-world application. ${ }^{7}$
One method for purposefully engaging end-users is the James Lind Alliance (JLA) Priority Setting Partnership (PSP). The JLA is a nonprofit initiative supported by the United Kingdom's National Institute for Health Research. Priority Setting Partnerships bring together groups that are often underrepresented in priority-setting initiatives, including patients, caregivers and clinicians, to identify and prioritize questions of greatest importance, ${ }^{8}$ shaping the health research agenda and alerting researchers and funders of what matters most to those using the evidence. ${ }^{9}$ These partnerships have been conducted across a range of topics, including

Competing interests: None declared.

This article has been peer reviewed.

Correspondence to: Adrian Wagg, adrian.wagg@ualberta.ca

CMAJ Open 2021. DOI:10.9778/cmajo.20190225 
dementia, urinary incontinence, Parkinson disease and fragility fractures. ${ }^{10-13}$

Given the strengths of this approach, we conducted a PSP that aimed to span the range of concerns in older adult health. Therefore, the goal of this PSP was to bring older adults, caregivers, clinicians and their representative organizations together to identify and prioritize the most important questions regarding the health of older adults to be addressed by future research.

\section{Methods}

\section{Study design}

We followed the JLA method for PSPs, involving a combination of surveys and workshops, overseen by a JLA adviser (K.C.). ${ }^{9}$ We used the Reporting Guideline for Priority Setting of Health Research (REPRISE) framework to report this study. ${ }^{14}$

\section{Steering group and partners}

We partnered with stakeholders who shared our goal and who helped promote this work to their groups (Appendix 1, available at www.cmajopen.ca/content/9/2/E522/suppl/DC1). Partners comprised, represented or served 1 or more target groups, including older adults ( $\geq 65 \mathrm{yr}$ ), caregivers and partners of older adults (e.g., spouse, family member, friend, neighbour) and front-line clinicians or social care providers (e.g., doctor, nurse, care aide, allied health provider, pharmacist, social worker, community or social service provider) working with older adults.

Simultaneously, we recruited a volunteer steering group by advertising to organizations that serve older adults and on the websites of public health and health service organizations in Alberta (Appendix 2, available at www.cmajopen.ca/content /9/2/E522/suppl/DC1). Investigators and the JLA adviser selected members of the steering group, which ultimately included 2 patients, 3 care partners (daughters), 3 clinicians (1 physician, 2 specialist nurses), 3 representatives from patient organization, the JLA adviser and the project team. The group met monthly to guide the research process and to represent our 3 constituent groups and the organizations serving these groups.

\section{Participants}

For both the initial and interim prioritization surveys, our target participants were older adults, their care partners, clinicians and social care providers who either lived or worked in Alberta, and representatives of agencies and organizations serving older adults. For the workshop, we recruited attendees from our partner groups.

\section{Process}

\section{Initial survey}

We collected initial data to identify unanswered questions by survey (Jan. 22 to May 2, 2018), according to JLA process. Acknowledging that issues important to older adults' health may not necessarily arise directly from clinical health care encounters, the steering group used the language of "unanswered questions" rather than the JLA term "treatment uncertainties." The survey used open-ended questions to ask respondents what mattered most to them about older adults' health within 6 topic areas, determined by the steering committee: aging well, health care practices or services, preventing illness or disease, diagnosis or treatment of illness or disease, managing symptoms or conditions (or supporting someone with health conditions) and maintaining mental health and social participation. The final section focused on demographic information to assess recruitment efforts and to categorize responses. We pilot tested the survey for acceptability and comprehension with steering group members and members of the organizations they represented as a convenience sample, then refined the survey for clarity before distribution.

We circulated the invitation to participate through our partners, the website of the Seniors Health Strategic Clinical Network, social media and by word-of-mouth. We distributed the survey (Appendix 3, available at www.cmajopen.ca/ content/9/2/E522/suppl/DC1) via Alberta Health Services' web-based resources, contacts with centres for older adults and other not-for-profit organizations catering to older adults, identified from an online directory. Participants completed the survey online or by paper submissions, returned in postage prepaid reply envelopes, as requested by either individual participants or their representative organizations.

Between May 28-Aug. 20, 2018, team members (H.M.H., A.W. and a research assistant) reviewed in duplicate and categorized them by content area to generate an initial taxonomy. Where necessary, we merged and rephrased similar and duplicate questions to create a summary question representing underlying responses. These were reviewed by the steering group. We removed submissions falling outside the scope of the PSP, including procedures or protocols relating to regulations or policies, advocacy on older adult issues, and housing and transportation not framed in connection to health. The steering group worked in pairs to review the 101 resulting summary questions to ensure the wording captured the underlying raw data.

\section{Assessment of uncertainty}

We assessed summary questions against published evidence to determine if they represented a knowledge gap. Working with library scientists, we assessed each question against systematic reviews in the Cochrane Database of Systematic Reviews and clinical guidelines from the National Institute for Health and Care Excellence and the Scottish Intercollegiate Guidelines Network, limited to evidence published in English between 2008 and 2018. If evidence was identified, we reviewed the content to determine the degree to which it answered the summary question (i.e., completely answered, partially answered or unanswered). We retained partially answered and unanswered questions. We critically appraised the quality of the evidence for questions identified as completely or partially answered using A Measurement Tool to Assess Systematic Reviews (AMSTAR 2). ${ }^{15}$ 


\section{Interim prioritization survey}

Given the broad nature of this PSP, we anticipated that most summary questions would be either partially or completely unanswered. As such, we distributed an interim prioritization survey (July 3-Aug. 2, 2018) in parallel with the assessment of uncertainty (Appendix 4, available at www.cmajopen.ca/ content/9/2/E522/suppl/DC1), using the same recruitment strategy as the initial survey. We asked respondents to review the summary questions and select the 10 they felt to be of greatest importance. We also requested basic demographic data to categorize respondents.

We applied the results from the uncertainty assessment results to the interim prioritization list to remove completely answered questions before team members (H.M.H., A.W. and a research assistant) assessed prioritization rankings. For the final workshop, we analyzed submissions within respondent groups to ensure equal weighting of high priority questions.

\section{Priority-setting workshop}

The final prioritization workshop, held in Calgary on Aug. 30, 2018, ranked the top areas for future research. We circulated an expression of interest to all stakeholders to identify a diverse mix of attendees from our 3 groups who were interested in participating in the 1-day, in-person event. The workshop objective was to facilitate reflection and discussion on the short list of summary questions, and to reach agreement on the top 10 most important questions.

The JLA adviser chaired the workshop. Attendees participated in conversations with small and large groups of mixed composition to discuss and prioritize the summary questions. Each of 3 small groups was led by an experienced JLA facilitator, employing a modified Nominal Group Technique. ${ }^{9}$ We aggregated small group rankings across the groups after each of 2 rounds and then presented the results for a final round of discussion and ranking. The workshop concluded when participants had reached consensus on the final ranked summary question list.

\section{Statistical analysis}

We used summary statistics to characterize survey and workshop participants.

\section{Ethics approval}

The PSP received research ethics board approval from the Health Research Ethics Board of the University of Alberta (Pro00070878). All participants provided informed consent.

\section{Results}

Forty-three groups, associations and organizations participated in the project (Appendix 2).

\section{Initial survey}

We received 88 (13\%) paper surveys and 592 (87\%) online responses, resulting in 670 surveys (excluding 10 returned with demographic information only). Respondent demographic characteristics are in Table 1. About half of participants
(52.4\%) were older adults and care partners with lived experience with the health of older adults (Table 2). In total, 101 summary questions were produced from over 3000 responses. The summary questions represented 24 content areas, albeit with some overlap (Figure 1).

\section{Assessment of uncertainty}

We determined that most $(66.3 \%)$ summary questions were unanswered, with one-third (29.7\%) assessed as partially answered (Table 3). The 4 completely answered questions related to symptom management in older adults with comorbidities ${ }^{16}$ diagnosis of delirium, ${ }^{17}$ timely and accurate diagnosis of dementia ${ }^{18,19}$ and prevention of isolation and loneliness in continuing care..$^{20} \mathrm{We}$ did not assess any evidence in support of the partially or completely answered questions as low or critically low quality.

\section{Interim prioritization survey}

The 101 summary questions formed the interim prioritization survey. We received 232 completed surveys; the distribution of respondents across the 3 target groups was similar to the initial survey $(53.0 \%$ older adults and caregivers; Table 1, Table 2).

We identified the highest priorities of the 97 unanswered summary questions for each respondent group, resulting in 22 final questions for the workshop (Appendix 5, available at www.cmajopen.ca/content/9/2/E522/suppl/DC1). The interim survey identified areas of shared importance across target groups, with 2 or more groups bringing forward 7 of the 22 shortlisted questions. For example, all 3 target groups identified the need for programs and services to combat caregiver burnout and stress as being of 1 of the 10 most important topics (ranked as fourth, eighth and tenth by health and social care workers, older adults and caregivers, respectively).

\section{Priority-setting workshop}

All final workshop attendees represented at least 1 constituent group, although most identified with more than 1 group, such as a clinician who was also a care partner for an aging parent. In total, 22 people participated in the workshop (Table 4). Attendee perspectives included health administration, nursing regulatory bodies, housing, advocacy and clinical care (nursing, allied health and medicine). Although older adults and caregivers were in the minority, many clinicians also represented this perspective.

Small group discussions in the workshop led to a preliminarily rank ordering of questions (Appendix 6, Figure 1, available at www.cmajopen.ca/content/9/2/E522/suppl/DC1). New small groups discussed and modified this aggregated rank order, and large group discussions (Appendix 6, Figure 2), facilitated by the JLA adviser, created a final prioritized list of the top 10 topics (Box 1).

The top 10 list included questions regarding strategies that best allow older adults to remain independent for as long as possible, and ways in which the health care system can be proactive in encouraging prevention of disease and disability and 


\begin{tabular}{|c|c|c|}
\hline \multirow[b]{2}{*}{ Respondent group } & \multicolumn{2}{|c|}{ No. $(\%)$ of respondents } \\
\hline & $\begin{array}{l}\text { Initial } \\
\text { survey } \\
n=670\end{array}$ & $\begin{array}{l}\text { Interim prioritization } \\
\text { survey } \\
n=232\end{array}$ \\
\hline Older adults & $219(32.7)$ & $66(28.4)$ \\
\hline Caregivers & $132(19.7)$ & $57(24.6)$ \\
\hline Health and social care workers* & $314(46.9)$ & $109(47.0)$ \\
\hline \multicolumn{3}{|l|}{ Professional background } \\
\hline $\begin{array}{l}\text { Aide (e.g., care aide, nurse assistant, therapy } \\
\text { assistant) }\end{array}$ & $7(2.2)$ & $1(0.9)$ \\
\hline Nurse (RN, RPN or LPN) & $92(28.8)$ & $35(32.1)$ \\
\hline Nurse practitioner & $2(0.6)$ & $4(3.7)$ \\
\hline Social worker & $44(13.8)$ & $18(16.5)$ \\
\hline $\begin{array}{l}\text { Allied health professional (physiotherapist, } \\
\text { occupational therapist, respiratory therapist, speech } \\
\text { and language pathologist, recreational therapist) }\end{array}$ & $112(35.1)$ & $22(20.2)$ \\
\hline Physician & $11(3.4)$ & $12(11.0)$ \\
\hline Pharmacist & $2(0.6)$ & $0(0)$ \\
\hline Dietician & $15(4.7)$ & $2(1.9)$ \\
\hline Manager or administrator & $9(2.8)$ & $6(5.5)$ \\
\hline Other & $11(3.4)$ & $7(6.4)$ \\
\hline No response & $14(4.4)$ & $2(1.8)$ \\
\hline \multicolumn{3}{|l|}{ Work setting } \\
\hline Primary and community care & $132(42.0)$ & $55(50.4)$ \\
\hline Acute care & $81(25.8)$ & $36(33.0)$ \\
\hline Continuing care & $118(37.6)$ & $35(32.1)$ \\
\hline Other & $32(10.2)$ & $10(9.2)$ \\
\hline Representatives from related agencies or organizations & $5(0.7)$ & $0(0)$ \\
\hline \multicolumn{3}{|c|}{$\begin{array}{l}\text { Note: } \mathrm{LPN}=\text { licensed practical nurse, } \mathrm{RN}=\text { registered nurse, } \mathrm{RPN}=\text { registered practical nurse. } \\
{ }^{*} \text { Participants could select more than } 1 \text { response. Subgroup percentages represent the frequency of each subgroup } \\
\text { relative to total number of health and social care workers. }\end{array}$} \\
\hline
\end{tabular}

be made more accessible. The list also included questions that address the geriatric-related knowledge and skills of health care providers and the ability of providers to consider the goals and wishes of older people regarding their care. Other questions considered the availability of dementia-related care, care transitions, health care system navigation and the care of caregivers, in addition to ways in which older people might receive sufficient time to discuss complex needs in a single clinical encounter.

\section{Interpretation}

Using the JLA approach, we engaged older adults, caregivers, clinicians and organizational representatives serving these groups to collaboratively prioritize the most important issues to be addressed by future research in older adults' health. The top 10 list largely supports the objective of improving quality of care and health outcomes for older adults, as well as calling for improved health literacy to allow older adults and their caregivers to fully benefit from the health care system. The list addresses various aspects of the health care system (e.g., navigation, rural accessibility, culture), provision of informal (e.g., caregiving) and formal care (e.g., older adultfriendly care, provider availability, continuity), and living well in older adulthood (e.g., with dementia, daily living).

A central theme appears to be independence, with the maintenance of independence ranked first within the final top 10 list. Other priority questions seem to support this theme. Improving continuity of care across care transitions may well decrease errors and poor outcomes that occur when unwell older adults are transferred between settings. ${ }^{21}$ The desire for the health system to proactively support health, rather than reacting to disease and disability, also reflects the priority of maintaining independence. The PSP places emphasis on preventive care and public health, which would allow people to maintain health and prevent avoidable 


\begin{tabular}{|c|c|c|c|c|}
\hline \multirow[b]{2}{*}{ Variable } & \multicolumn{2}{|c|}{$\begin{array}{l}\text { No. }(\%) \text { of respondents to } \\
\text { initial survey* }\end{array}$} & \multicolumn{2}{|c|}{$\begin{array}{l}\text { No. }(\%) \text { of respondents to } \\
\text { interim prioritization } \\
\text { survey* }\end{array}$} \\
\hline & $\begin{array}{l}\text { Older } \\
\text { adults } \\
n=219\end{array}$ & $\begin{array}{c}\text { Caregivers } \\
n=132\end{array}$ & $\begin{array}{l}\text { Older } \\
\text { adults } \\
n=66\end{array}$ & $\begin{array}{c}\text { Caregivers } \\
n=57\end{array}$ \\
\hline Age, yr, mean \pm SD & $73.5 \pm 6.4$ & $57.5 \pm 9.4$ & $72.7 \pm 5.8$ & $60.3 \pm 9.9$ \\
\hline Sex, female $†$ & $155(70.8)$ & $116(87.9)$ & $50(75.8)$ & 47 (82.5) \\
\hline \multicolumn{5}{|l|}{ Ethnicity } \\
\hline $\begin{array}{l}\text { North American Indigenous (e.g., } \\
\text { First Nations, Metis or Inuk [Inuit]) }\end{array}$ & $3(1.4)$ & $4(3.0)$ & $0(0)$ & $1(1.8)$ \\
\hline Other North American & $110(50.2)$ & $61(46.2)$ & $29(43.9)$ & $26(45.6)$ \\
\hline European & $120(54.8)$ & $68(51.5)$ & $41(62.1)$ & $32(56.1)$ \\
\hline Asian & $15(6.8)$ & $8(6.1)$ & $1(1.5)$ & $3(5.3)$ \\
\hline Other & $3(1.4)$ & 0 & $1(1.5)$ & 0 \\
\hline Prefer not to say & $3(1.4)$ & $4(3.0)$ & $0(0)$ & $0(0)$ \\
\hline \multicolumn{5}{|c|}{$\begin{array}{l}\text { Note: } \mathrm{SD}=\text { standard deviation. } \\
\text { *Unless indicated otherwise. } \\
\text { †One individual responded as not identifying as male or female and } 5 \text { individuals responded as preferring not to } \\
\text { answer. } \\
\text { †Participants could select more than } 1 \text { response. }\end{array}$} \\
\hline
\end{tabular}

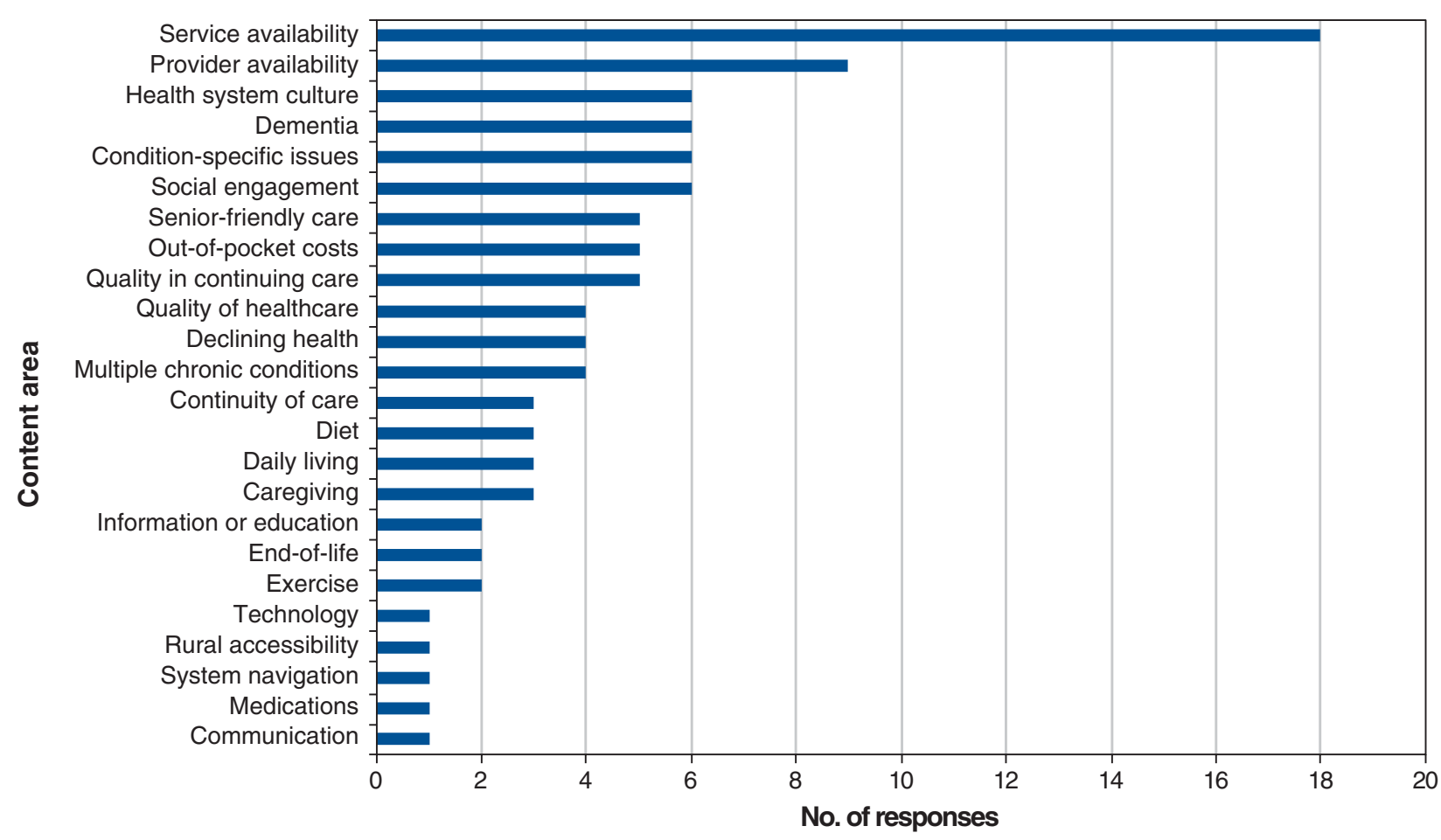

Figure 1: Content areas regarding the health of older adults, represented by the 101 summary questions identified in the initial survey. 


\begin{tabular}{|lc|}
\hline $\begin{array}{l}\text { Table 3: Assessment of uncertainty of } 101 \\
\text { summary questions compiled from } \\
\text { surveys }\end{array}$ & $\begin{array}{l}\text { No. (\%) of } \\
\text { questions } \\
n=101\end{array}$ \\
\hline Outcome & $4(4.0)$ \\
\hline Fully answered question & $30(29.7)$ \\
\hline Partially answered question & $67(66.3)$ \\
\hline Unanswered question & $\begin{array}{l}{ }^{*} \text { Topics of fully answered questions include symptom } \\
\text { management in older adults with comorbidities, } \\
\text { diagnosis of delirium, } \\
\text { dementianely, accurate diagnosis of } \\
\text { in continuing care. }{ }^{20}\end{array}$ \\
\hline
\end{tabular}

\begin{tabular}{|lr|}
\hline $\begin{array}{l}\text { Table 4: Workshop attendees by target } \\
\text { group }\end{array}$ & $\begin{array}{c}\text { No. (\%) of } \\
\text { attendees* } \\
n=22\end{array}$ \\
\hline Group & $5(23.0)$ \\
\hline Older adults & $6(27.0)$ \\
\hline Caregivers & $19(63.0)$ \\
\hline Health or social care workers & \\
\hline $\begin{array}{l}\text { *Eight attendees identified as representing more than } 1 \\
\text { target group. }\end{array}$ \\
\hline
\end{tabular}

Box 1: Top 10 list of priority areas in older adult health for future research

1. What strategies best allow older adults to remain independent for as long as possible?

2. In what ways can the health care system become more proactive, instead of reactive, in addressing and encouraging the prevention of disease or disability?

3. In what ways can health care service accessibility for older adults living in a rural community be improved?

4. How can geriatric-related knowledge among health care providers be improved and applied when caring for older adults?

5. What are the optimal ways to ensure health care providers take into consideration the goals and wishes of older adults during care and treatment?

6. What can be done to increase the availability of dementiarelated care and services for older adults?

7. What interventions and programs best enable older adults to more easily navigate the health care system?

8. What are the most effective programs and services that can be provided to caregivers to combat burnout and stress when caring for older adults?

9. What is the most effective strategy to ensure an optimal transition between care settings for older adults?

10. How can health care encounters be restructured to allow older adults sufficient time with providers to discuss complex concerns in 1 appointment? illness, ${ }^{22}$ delaying the onset of disability and preserving independence for as long as possible. ${ }^{23}$

Although recently conducted Canadian PSPs have focused on dementia ${ }^{10}$ and frailty, ${ }^{24}$ we purposefully spanned issues affecting the lives of older adults and their caregivers to assess how such questions compared in terms of priority, weighing the issues, conditions and diseases together. This is not to say that there is not value in condition-specific PSPs for older adults. In fact, the dementia and frailty PSPs both provide researchers and funders prioritized lists for targeted research in those areas. However, for organizations that advocate for and fund research related to older adults' health and wellbeing more broadly, this PSP adds value by highlighting questions that lay outside disease or condition areas.

Although it may be too much to expect health services to take the lead and be effective with all determinants of the health of older adults, many of the identified questions reflect the interconnectedness of health and social care in determining the health of older adults. According to a recent critique of the World Health Organization's proposal for a decade of healthy aging, ${ }^{25}$ the approach of distinguishing between health service and social support reflects a systems-based delivery view. Although this project provides little guidance on how the spectrum of needs might be addressed, we recognize that providing answers will require a holistic, integrated approach, where distinctions between health and social support needs should be integrated.

There is a knowledge translation opportunity related to summary questions that were identified as completely answered. Although evidence is available, it has not reached knowledge users. A knowledge translation product, such as publications in both academic and professional media, would assist in moving evidence to end-users, ${ }^{26}$ and there is an opportunity to close this knowledge gap. Thus, as part of the dissemination plan, the Strategic Clinical Network has launched a targeted knowledge synthesis grant and employed a postdoctoral fellow to conduct some of this work. An associated dissemination plan has included meetings with research funders in Alberta, widespread publicity regarding the report from the PSP, feedback to participants and participating organizations and a public meeting.

\section{Limitations}

Given the method of data collection, we were unable to assess our survey response rate and the potential for response bias, similar to most surveys of this nature. Although unlikely, there may have been crossover in those participating in the initial and interim prioritization surveys and the workshop.

Few older adults participated in the final workshop. Despite partnering with seniors' centres and care facilities, both the surveys and the workshop were limited by the underrepresentation of Indigenous older people, people older than 80 years, people residing in long-term care and people with potentially stigmatizing conditions. We highlighted this issue at the start of the workshop to encourage participants to consider these underrepresented groups. Recognition of who is, and is not, at the prioritization table is needed for balanced conversations. 
Given resource limitations, the surveys were available in English only. During our assessment of uncertainty, we searched only guidelines and systematic reviews, rather than primary studies, because of limitations in resources and time. This may have led to misclassification of some submitted questions.

\section{Conclusion}

We call upon stakeholders to advocate for uptake of the top 10 list of priority topics in older adult health. Patients, care partners and clinicians can participate in studies producing new knowledge. Researchers can generate evidence on one of the top 10 questions. Research funders can award grants to projects that address issues prioritized by end-users. Together, we can make great strides to meet the needs of patients and care partners, and of the health and social care providers who serve them.

\section{References}

1. Canada's population estimates: age and sex, July 1, 2018. Cat no 11-001-X. Ottawa: Statistics Canada; modified 2019 Jan. 25.

2. Treasury Board and Finance. Population projections: Alberta and Census Divisions, 2019-2046. Government of Alberta; 2020.

3. Millar A, Hanson HM, Wagg AS; Seniors Health Strategic Clinical Network. Seniors Health Strategic Clinical Network: Age proofing Alberta through innovation. CMA7 2019;191(Suppl):S19-21.

4. Canada's Strategy for Patient Oriented Research: Improving health outcomes through evidence-informed care. Ottawa: Canadian Institutes for Health Research; 2011.

5. Clancy C, Collins FS. Patient-Centered Outcomes Research Institute: the intersection of science and health care. Sci Transl Med 2010;2:37 cm18.

6. Yiu V, Woods S, Gordon D, et al. The Patient First Strategy. Edmonton: Alberta Health Services; 2015.

7. Patrick K, Kebbe M, Aubin D. A home for patient-oriented research. CMAJ 2018;190:E607.

8. Crowe S, Fenton M, Hall M, et al. Patients', clinicians' and the research communities' priorities for treatment research: there is an important mismatch. Res Involv Engagem 2015;1:2.

9. The fames Lind Alliance Guidebook. Version 7. Southampton (UK): National Institute for Health Research; 2018.

10. Bethell J, Pringle D, Chambers LW, et al. Patient and public involvement in identifying demenia research priorities. 7 Am Geriatr Soc 2018;66:1608-12.

11. Buckley BS, Grant AM, Tincello DG, et al. Prioritizing research: patients, carers, and clinicians working together to identify and prioritize important clinical uncertainties in urinary incontinence. Neurourol Urodyn 2010;29:708-14.

12. Deane KHO, Flaherty H, Daley DJ, et al. Priority setting partnership to identify the top 10 research priorities for the management of Parkinson's disease. BM7 Open 2014;4:e006434.

13. Fernandez MA, Arnel L, Gould J, et al. Research priorities in fragility fractures of the lower limb and pelvis: a UK priority setting partnership with the James Lind Alliance. BM7 Open 2018;8:e023301.

14. Tong A, Synnot A, Crowe S, et al. Reporting guideline for priority setting of health research (REPRISE). BMC Med Res Methodol 2019;19:243.

15. Shea BJ, Reeves BC, Wells G, et al. AMSTAR 2: a critical appraisal tool for systematic reviews that include randomised or non-randomised studies of healthcare interventions, or both. BMF 2017;358:j4008.

16. Multimorbidity: clinical assessment and management. London (UK): National Institute for Health and Care Excellence (NICE); 2016. Available: www.nice.org. uk/guidance/NG56/chapter/Recommendations\#principles-of-an-approach-to -care-that-takes-account-of-multimorbidity (accessed 2021 Feb. 22).
17. Delirium: prevention, diagnosis and management. London (UK): National Institute for Health and Care Excellence (NICE); 2010, updated 2019 Mar. 14. Available: www.nice.org.uk/guidance/cg103 (accessed 2021 Feb. 22).

18. Canadian Task Force on Preventive Health Care; Pottie K, Rahal R, Jaramillo A, et al. Recommendations on screening for cognitive impairment in older adults. CMA7 2016;188:37-46.

19. Dementia: assessment, management and support for people living with dementia and their carers. London (UK): National Institute for Health and Care Excellence; 2018. Available: www.nice.org.uk/guidance/ng97 (2021 Feb. 22).

20. Older people with social care needs and multiple long-term conditions. London (UK): National Institute for Health and Care Excellence; 2015. Available: www.nice.org.uk/guidance/ng22 (accessed 2021 Feb. 22).

21. Brown MM. Transitions of care. In: Daaleman T, Helton M, editors. Chronic Illness Care. Cham (Switzerland): Springer; 2018:369-73.

22. Let's talk about aging: aging well in Alberta. A report by the Office of the Chief Medical Officer of Health. Edmonton: Government of Alberta; 2013.

23. Haber D. Health promotion and aging: practical applications for bealth professionals. 6th ed. New York: Springer Publishing Company; 2013:1-513.

24. Bethell J, Puts MTE, Sattar S, et al. The Canadian Frailty Priority Setting Partnership: research priorities for older adults living with frailty. Can Geriatr 7 2019;22:23-33.

25. Lloyd-Sherlock P, Kalache A, Kirkwood T, et al. WHO's proposal for a decade of healthy ageing. Lancet 2019;394:2152-3.

26. Straus SE, Tetroe J, Graham I. Defining knowledge translation. CMAJ 2009;181:165-8.

Affiliations: Seniors Health Strategic Clinical Network (Hanson, Wagg), Alberta Health Services; Department of Community Health Sciences (Hanson), Cumming School of Medicine, University of Calgary, Calgary, Alta.; James Lind Alliance (Cowan), National Institute for Health Research Evaluation, Trials and Studies Coordinating Centre, University of Southampton, Southampton, UK; Division of Geriatric Medicine (Wagg), Faculty of Medicine \& Dentistry, University of Alberta, Edmonton, Alta.

Contributors: Adrian Wagg conceived and designed the study. All of the authors contributed to the acquisition, analysis and interpretation of data. All of the authors drafted the manuscript, revised it critically for important intellectual content, gave final approval of the version to be published and agreed to be accountable for all aspects of the work.

Funding: Funding for this initiative was provided by the Seniors Health Strategic Clinical Network, Alberta Health Services.

Content licence: This is an Open Access article distributed in accordance with the terms of the Creative Commons Attribution (CC BY-NC-ND 4.0) licence, which permits use, distribution and reproduction in any medium, provided that the original publication is properly cited, the use is noncommercial (i.e., research or educational use), and no modifications or adaptations are made. See: https://creativecommons.org/licenses/ by-nc-nd/4.0/

Data sharing: All data herein are accessible to other interested parties by application to the corresponding author.

Acknowledgements: The authors acknowledge their partners for their support of this project and assistance with recruitment. The authors thank the respondents who took part in the surveys, and the final workshop attendees for sharing their time and perspectives. They also thank Knowledge Resource Services, Alberta Health Services, for their contribution of staff and expertise to support the literature search and appraisal phase of this project. The authors recognize the important role that the facilitators played in the success of the final workshop.

Supplemental information: For reviewer comments and the original submission of this manuscript, please see www.cmajopen.ca/content/9/2/ E522/suppl/DC1. 